\title{
Erratum to: From Scholarly Dialogue \\ to Social Movement: Considerations \\ and Implications for Peace Through \\ Commerce
}

Marc Lavine

\section{Erratum to: J Bus Ethics \\ DOI 10.1007/s10551-010-0410-8}

Due to an editing error, the second sentence in the abstract of the article includes an errant word at the end. The sentence should read:

"Because social movement scholarship explores the ability of the collective interests to achieve social change it provides a useful lens through which to consider PTC's maturation and, more broadly, the rise of scholarly conversations into social movements."

We apologize to the author and to the readers for any confusion this causes.

Department of Management and Marketing, University of Massachusetts Boston, 100 Morrissey Boulevard, Boston, MA 02521, U.S.A. E-mail:marc.lavine@umb.edu

The online version of the original article can be found under doi:10.1007/s10551-010-0410-8. 